\title{
mRNA-to-protein translation in hypoxia
}

\author{
Nancy T. Chee, Ines Lohse and Shaun P. Brothers ${ }^{*}$ (D)
}

\begin{abstract}
Cells respond to hypoxia by shifting cellular processes from general housekeeping functions to activating specialized hypoxia-response pathways. Oxygen plays an important role in generating ATP to maintain a productive rate of protein synthesis in normoxia. In hypoxia, the rate of the canonical protein synthesis pathway is significantly slowed and impaired due to limited ATP availability, necessitating an alternative mechanism to mediate protein synthesis and facilitate adaptation. Hypoxia adaptation is largely mediated by hypoxia-inducible factors (HIFs). While HIFs are well known for their transcriptional functions, they also play imperative roles in translation to mediate hypoxic protein synthesis. Such adaptations to hypoxia are often hyperactive in solid tumors, contributing to the expression of cancer hallmarks, including treatment resistance. The current literature on protein synthesis in hypoxia is reviewed here, inclusive of hypoxia-specific mRNA selection to translation termination. Current HIF targeting therapies are also discussed as are the opportunities involved with targeting hypoxia specific protein synthesis pathways.
\end{abstract}

Keywords: Hypoxia, mRNA-to-protein translation, HIF, Hypoxia-inducible factor, Cancer, HIF inhibitors

\section{Introduction}

Hypoxia is vaguely defined as the decrease in oxygen availability below normal tissue levels. Due to varying oxygen tensions in different tissues, what constitutes low oxygen conditions also varies $[1,2]$. There are generally two types of hypoxia: acute and chronic. Acute hypoxia is a rapid and transient decrease in $\mathrm{pO}_{2}$ that may be caused by an obstruction of the airways, acute hemorrhaging or abrupt cardiorespiratory failure. If the stress is not alleviated, acute hypoxia can cause damage to those systems, contributing to the development of chronic hypoxia. Chronic hypoxia occurs when oxygen supply is limited for long periods of time. Chronic hypoxia is seen in solid tumors, where oxygen consumption outweighs oxygen influx [3]. Due to unstable homeostasis in solid tumors, cells can quickly cycle between normoxic and hypoxic states, adding another layer of microenvironmental complexity in cancer [4].

A core characteristic of the tumor microenvironment, hypoxia is present in all solid tumors and has been proposed to also influence liquid cancers [3, 5-8]. Although tumors are vascularized, rapid angiogenesis results in the formation of an ineffective and leaky vascular

\footnotetext{
*Correspondence: spbrothers@hotmail.com; sbrothers@med.miami.edu Department of Psychiatry and Behavioral Sciences, University of Miami Miller School of Medicine, 1501 NW 10th Avenue, Miami, FL 33136, USA
}

network often containing dead ends [9]. While the exterior cells of the tumor mass are more likely to receive sufficient oxygen, the core of the tumor lacks oxygen and generally displays areas of severe chronic hypoxia [10]. Hypoxic regions are not limited to the tumor core, and can occur throughout the mass even in close proximity to what histologically appears to be a functional blood vessel, suggesting that demand-to-supply imbalance contributes to hypoxic microenvironments [10].

Hypoxic tumor cells can survive due to changes in cellular processes partially mediated by the accumulation and activity of hypoxia-inducible factors (HIFs). Data support the hypothesis that chemotherapy and radiation resistance seen in cancers are at least partially due to increased HIF activity [11-14]. Hence, tumorigenesis may be inhibited by blocking HIF activity in these hypoxic cells, making HIFs an attractive target for treating some cancers [15-19]. HIFs are well-known as transcription factors. However, their role in mRNA-to-protein translation is also imperative to cell survival since the canonical protein synthesis pathway is impaired in hypoxia.

As one of the most energy-consuming processes in the cell, translation requires enormous amounts of ATP synthesized in healthy cells [20]. Cells metabolize glucose to generate ATP, a process that requires oxygen. Therefore, low oxygen supply results in decreased rate of global

(C) The Author(s). 2019 Open Access This article is distributed under the terms of the Creative Commons Attribution 4.0 International License (http://creativecommons.org/licenses/by/4.0/), which permits unrestricted use, distribution, and 
mRNA-to-protein translation in the cell due to decreased ATP availability. Because the canonical translation pathways require large amounts of ATP generated in the presence of oxygen, hypoxia limits this translation pathway, thus necessitating an alternative translation pathway to efficiently synthesize proteins in hypoxic environments $[21,22]$. HIFs are major regulators of the alternative hypoxia-induced translation pathway activation.

\section{Hypoxia-inducible factors}

HIFs are a family of proteins that mediate cellular adaptation to hypoxia. Heterodimeric HIF transcription factors consist of HIF $\alpha$ and HIF $\beta$ subunits. The HIF $\alpha$ subunits are cytosolic, constitutively synthesized and tightly regulated. The HIF $\beta$ subunit (aryl hydrocarbon receptor nuclear translocator (ARNT)), is a constitutively active DNA binding protein that remains in the nucleus.

The HIF $\alpha$ family of proteins is comprised of three subtypes: HIF $1 \alpha$, HIF $2 \alpha$ and HIF3 $\alpha$. HIF $1 \alpha$ is ubiquitously expressed at low, basal levels in all tissues in healthy individuals in normoxia. HIF1 $\alpha$ expression increases with transient, acute hypoxia exposure in most tissues and decreases to basal levels after reaching its maximum expression [23, 24]. HIF2 $\alpha$ and HIF3 $\alpha$ expressions are more tissue specific. HIF $2 \alpha$ is preferentially expressed in organs that experience greater hypoxia, such as the pancreas, liver and kidneys [25, 26]. HIF2 $\alpha$ increases expression with prolonged, chronic hypoxia exposure, suggesting that HIF1 $\alpha$ and HIF2 $\alpha$ subtypes play different roles in cellular adaptation to acute and chronic hypoxia $[23,24]$. HIF3 $\alpha$ is preferentially expressed in the heart, lungs, cerebellum and eyes and has been found to inhibit HIF $1 \alpha$ and HIF $2 \alpha$ activity [27]. The role of HIF $3 \alpha$ in hypoxic physiology remains to be elucidated. HIF $\alpha$ expression increases with continuous exposure to hypoxia and the duration of exposure to reach maximal HIF expression depends on the tissue type [23].

Structurally, HIF $1 \alpha$ and HIF $2 \alpha$ are highly homologous, containing the same motifs and domains. They both contain basic-helix-loop-helix (bHLH) and Per-Arnt-Sim (PAS) domains, which are required for DNA-binding and heterodimerization with ARNT in response to hypoxia, respectively [28]. HIF $1 \alpha$ and HIF $2 \alpha$ also contain transcriptional activation domains at the $\mathrm{N}$-terminus $(\mathrm{N}-\mathrm{TAD})$ and the $\mathrm{C}$-terminus $(\mathrm{C}-\mathrm{TAD})$ that are required to activate transcription of hypoxia-inducible genes and are subject to regulation by hydroxylation in normoxia [17]. The most differences in structure of the two isoforms are within the N-TAD region. The N-TAD is responsible for recognizing transcriptional target genes and due to the differences found in the N-TAD between HIF1 $\alpha$ and HIF $2 \alpha$, these proteins may target sets of different genes [29]. These two subtypes also contain an oxygen-dependent degradation domain (ODDD), required for regulation by oxygen-dependent proteins that degrade the HIFs in normoxia [30-32].

HIF $3 \alpha$ is structurally similar to HIF $1 \alpha$ and HIF $2 \alpha$ as it contains bHLH-PAS domains, ODD domains and $\mathrm{N}-\mathrm{TAD}$, as seen in Fig. 1. Unlike HIF1 $\alpha$ and HIF2 $\alpha$, however, HIF3 $\alpha$ lacks the C-TAD, which plays a role in HIF stabilization and transcription activation in HIF1 $\alpha$ and HIF $2 \alpha$. The absence of C-TAD in HIF3 $\alpha$ suggests a secondary function independent of its transcriptional activity $[17,33]$. Also indicative of a secondary function, HIF3 $\alpha$ contains a unique leucine zipper domain, which may facilitate DNA binding and protein-protein interactions. HIF3 $\alpha$ is subject to extensive alternative splicing that yields at least six different splice variants that may target different genes or have functions that are entirely independent from transcription [34]. Some of these splice variants, especially HIF3 $\alpha 4$, negatively regulate the transcriptional roles of HIF1 $\alpha$ and HIF $2 \alpha$ by direct binding [35]. Different splice variants of HIF1 $\alpha$ that lack the ODDD and TAD have also been found, although the functions of these variants have yet to be elucidated [36].

Like the HIF $\alpha$ subunits, the ARNT subunit contains bHLH and PAS domains. However, it does not contain the N-TAD region or the ODD domain, suggesting its oxygen-independent expression. ARNT is a nuclear

\begin{tabular}{|c|c|c|c|c|c|c|}
\hline HIF $1 \alpha$ & bHLH & PAS & ODDD & N-TAD & C-TAD & \\
\hline HIF $2 \alpha$ & bHLH & PAS & ODDD & N-TAD & C-TAD & TAD \\
\hline HIF3 $\alpha$ & bHLH & PAS & ODDD & N-TAD & Leu-Zipper & \\
\hline ARNT & bHLH & PAS & & C-TAD & & \\
\hline
\end{tabular}


translocator involved in many different cellular processes that aid protein translocation from the cytosol or the nuclear membrane into the nucleus. Hence, ARNT is ubiquitously and constitutively expressed. It is involved in cancer progression, chemotherapy resistance, wound healing and immune response pathophysiology [37-40].

HIFs are mostly known for their function as transcription factors, altering the transcriptome to mediate cellular response to hypoxia. Generally, HIF transcriptional target genes stimulate cell survival, metabolism, angiogenesis, metastasis and $\mathrm{pH}$ regulation in adaptation to low oxygen and increased intracellular acidity. Target genes include EPO, VEGF, GLUT-1, OCT4, CXCR4 and $L D H$, among a plethora of others $[41,42]$. Despite the structural and sequence homology between HIF1 $\alpha$ and HIF $2 \alpha$, these two proteins target distinct genes for transcription, as well as some overlapping genes. The role of HIF3 $\alpha$ in transcription is not as well elucidated as its counterparts. HIF3 $\alpha$ appears to be a negative regulator of gene expression in hypoxia by preventing HIF1 $\alpha$ mediated transcription activation [35, 43]. HIF3 $\alpha$ reduces HIF1 and HIF $2 \alpha$ activity by competing for HIF $1 \beta$ subunit binding [43]. HIF3 $\alpha$ also activates transcription of genes that are not targeted by HIF1 $\alpha$ or HIF $2 \alpha$, such as LC3C, REDD1 and SQRDL [44].

\section{HIF regulation}

HIF $1 \alpha$ and HIF $2 \alpha$ are well characterized in their roles as transcription factors [41]. In hypoxia, HIF $\alpha$ subunits accumulate and translocate to the nucleus where it dimerizes with ARNT. The HIF/ARNT heterodimer recruits p300/CBP, forming a complex that binds to the hypoxia response elements (HRE) in promoter regions to activate target gene transcription [17, 41]. To prevent increased HIF activity in normoxia, HIFs are tightly regulated by different pathways and enzymes. HIFs undergo proline hydroxylation, ubiquitination, SUMOylation, S-nitrosylation, asparagine hydroxylation and phosphorylation to promote HIF degradation.

One of the major HIF regulatory proteins is HIF-prolyl hydroxylase 2 (HIF-PH2) that belongs to the prolyl hydroxylase domain enzyme (PHD) family. PHDs are a major oxygen-sensing protein family that, upon binding to oxygen, hydroxylates different target protein to initiate a cellular response. HIF-PHD hydroxylates HIFs at proline residues (pro ${ }^{402}$ and pro ${ }^{564}$ in HIF $1 \alpha$, pro ${ }^{405}$ and pro $^{531}$ in HIF2 $\alpha$, pro ${ }^{492}$ in HIF3 $\alpha$ ) in the HIF ODDD [45-48]. These modifications facilitate the recruitment of von Hippel-Lindau ubiquitin ligase complex (pVHLE3 ligase complex) that ubiquitinates HIF $\alpha$, promoting proteasomal degradation [46].

HIF1 $\alpha$ is also subject to SUMOylation, which ultimately stabilizes the protein and enhances its transcriptional activity. HIF1 $\alpha$ is SUMOylated at residues lys ${ }^{398}$ and lys ${ }^{477}$ in the ODD domain and may modulate other post-translational modifications, such as ubiquitination, to increase stability and activity in vitro and in vivo $[49,50]$. A SUMO moiety is transferred from the E1-activating enzyme to the E2-conjugation enzyme, particularly Ubc9, which then carries the SUMO moiety to the target protein [51]. SUMO E3-ligase enzymes then mediate the final transfer of the SUMO from the E2-conjugation enzymes to the HIF1 $\alpha$ lysine residues. While the SUMOylation of HIF1 $\alpha$ increases its transcriptional activity, HIF1 $\beta$ is also SUMOylated at lys ${ }^{245}$ which decreases HIF $1 \alpha$ transcriptional activity [52]. While it is generally accepted that SUMOylation in hypoxia leads to HIF $1 \alpha$ stabilization and increased transcriptional activity, there are studies that demonstrate increased HIF1 $\alpha$ degradation after SUMOylation, making the underlying biology unclear [53]. SUMOylation also has an important role in promoting HIF2 $\alpha$ transcriptional activity. Hypoxia associated factor (HAF), a HIF1 $\alpha$-E3 ligase, is SUMOylated under hypoxic conditions and binds to the DNA upstream of the HRE in the promoter region of HIF2 $\alpha$ target genes. This binding promotes HIF2 $\alpha$ binding to the HRE, activating its transcriptional activity [54].

As hypoxic exposure progresses, nitric oxide (NO) levels also increase, leading to HIF $\alpha$ S-nitrosylation. HIF1 $\alpha$ is S-nitrosylated at cysteine residues cys $^{520}$ and cys $^{800}$. S-nitrosylation at $\mathrm{Cys}^{520}$, which lies within the ODD domain of HIF $1 \alpha$, increases the stability of the protein and impairs degradation by blocking prolyl hydroxylation and preventing ubiquitination. S-nitrosylation of residue cys ${ }^{800}$ promotes HIF1 $\alpha$ binding to transcriptional co-factors, such as p300 and CBP, ultimately enhancing its transcriptional activity [55-57].

Additionally, HIF $\alpha$ transcriptional activity is inhibited in normoxia by an asparagine hydroxylase, factor-inhibiting hypoxia-inducible factor (FIH). FIH catalyzes HIF $\alpha\left(\right.$ asp $^{803}$ ) hydroxylation in the C-TAD, the binding sites of co-transactivators $\mathrm{p} 300 / \mathrm{CBP}$ that promote transcription of HIF target genes [58]. Hydroxylation of C-TAD prevents $\mathrm{p} 300 / \mathrm{CBP}$ co-activators from binding to HIFs, ultimately blocking hypoxia-response element promoter binding $[59,60]$. Because HIF-PHD and FIH use oxygen as co-substrates to hydroxylate HIFs, hydroxylation cannot occur in hypoxia, causing HIF stabilization and accumulation. HIFs can translocate to the nucleus to initiate transcription or can remain in the cytoplasm to initiate translation of hypoxia-responsive proteins (Fig. 2) [3, 61]. Ineffective or faltered HIF regulation by PHDs or FIH may lead to cancer [62-65].

HIF $1 \alpha$ is also regulated by cyclin-dependent kinase 2 (Cdk2) cell-cycle regulator protein. Cdk2 phosphorylates $\operatorname{ser}^{668}$ of HIF1 $\alpha$ in normoxia, inhibiting proteasomal degradation and activating lysosomal degradation [59]. Initiating lysosomal degradation as opposed to proteasomal 


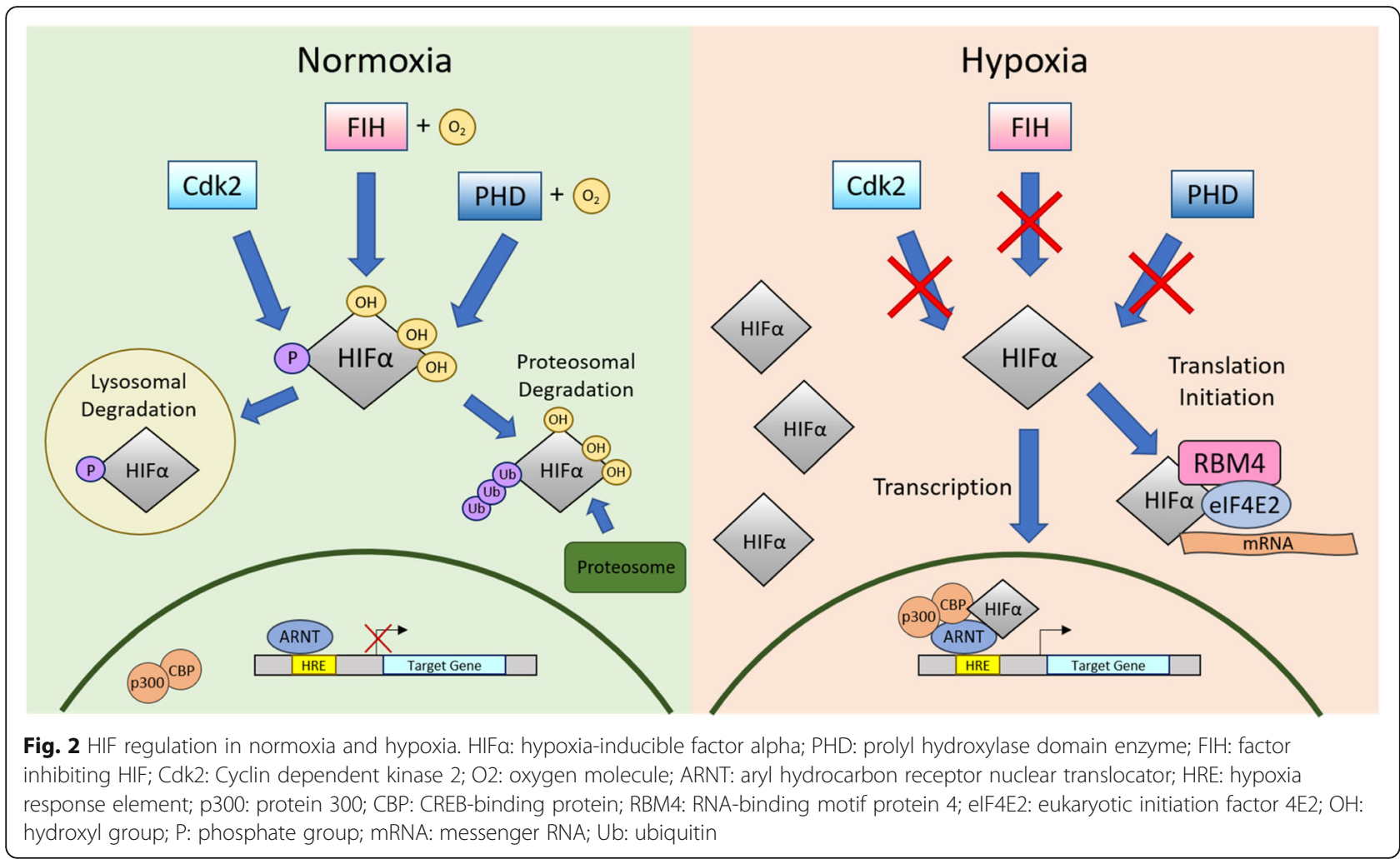

degradation ensures a secondary mechanism of HIF regulation in normoxia. In hypoxia, Cdk2 is inhibited, allowing HIF $1 \alpha$ to accumulate to initiate cellular responses. Another cell cycle regulator protein Cdk1 also phosphorylates HIF1 $\alpha \operatorname{ser}^{668}$ to promote lysosomal degradation in normoxia. In hypoxia, accumulated HIF1 $\alpha$ bind to and sequester Cdk1, inhibiting the lysosomal degradation pathway $[59,66]$.

In addition to these methods of HIF $\alpha$ regulation by other proteins, non-coding RNAs also play an important role in mediating cellular response to hypoxia. One of the most well-elucidated non-coding RNAs in hypoxia are micro-RNA-429 (miRNA-429) and micro-RNA-210 (miRNA-210), which has been shown to create a negative feedback look with HIF1 $\alpha[67,68]$. These two miRNAs have been shown to directly bind to the 3' UTR of the HIF $1 \alpha$ gene, ultimately decreasing the expression of HIF1 $\alpha$. Interestingly, these miRNAs are also the target genes of HIF $1 \alpha$, creating a negative feedback look of HIF $1 \alpha$ expression in hypoxia. HIFs are also regulated by hypoxia-responsive long non-coding RNA (HRL) [69, 70]. HRLs have a variety of functions in hypoxic cancers as they have been associated with increased tumorigenesis, ionizing radiation therapy resistance and metastasis [69-71]. HRLs are transcriptional targets of HIFs and unlike miRNAs, HRLs create a positive feedback by stabilizing HIFs by disrupting the HIF-VHL interaction, thus resulting in HIF accumulation [72].

\section{mRNA-to-protein translation and hypoxia}

Hypoxia significantly alters general cellular processes that maintain housekeeping functions. While transcription and transcriptomic changes in hypoxia are relatively well elucidated, that of translation is less well-known as much of it remained a mystery until 2012. Uniacke et al. discovered the mechanism of protein synthesis in hypoxia that is directly mediated by HIF $2 \alpha$. This discovery opened doors to further understanding the mechanisms and regulations of translation in hypoxia.

mRNA-to-protein translation consists of three steps driven by eukaryotic translation factors: initiation by initiation factors (eIFs), elongation by elongation factors (eEFs) and termination by release factors (eRFs). Translation factors that promote each step are generally active in normoxia though some are inactive in hypoxia. Cells adapt to these hypoxia-induced changes by activating alternative transcription pathways and protein synthesis machinery to continue to synthesize proteins necessary to promote cell survival in low energy and low oxygen environments.

\section{Hypoxia specific mRNA translation}

Hypoxic protein synthesis is geared towards adaptation that is initiated through mechanisms of mRNA selection for translation. There are several proposed mechanisms that contribute to mRNA selectivity in hypoxia: upstream open-reading frame (uORF)-mediated mRNA 
regulation, endoplasmic reticulum-mediated mRNA selection, IRES-dependent translation initiation and the presence of ribosomal hypoxia-response elements (rHRE) in the mRNA recognized by the hypoxic translation machinery [73-77].

uORFs are short sequences that lie within the 5' UTR region upstream of the protein coding sequence start codon, also called the main open-reading frame (mORF). The uORF is an essential cis-acting translation regulatory component that interacts with proteins that promote mORF translation or interacts directly with the ribosome, ultimately preventing mORF translation [78, 79]. Some $40-50 \%$ of all human mRNA transcripts contain at least one uORF that regulates mORF translation [78]. uORF regulation can decrease protein expression by 30 to $80 \%$ of its expression in normoxia [80]. In hypoxia, uORFs regulate HIF-mediated gene expression changes by allowing the scanning ribosome to bypass the uORF start codon, uAUG, allowing for $\mathrm{mAUG}$ recognition and mORF translation [81]. Translation of some mRNAs, such as $E P O, G A D D 34$ and $V E G F$, rely on the presence of uORFs to activate translation distinctly in hypoxia and not as significantly in normoxia [77, 81-83].

Another mechanism that results in selective mRNA translation in hypoxia is the partitioning and recruitment of mRNAs to the endoplasmic reticulum (ER) [77]. Many mRNAs transcribed in hypoxia contain highly conserved $5^{\prime}$ and 3' UTR elements that promote mRNA localization to the ER, where translation takes place [73, 74, 77]. Signal recognition particles (SRPs) recognize and bind to sequences in the conserved untranslated region (UTR) of mRNA to deliver it to the SRP-binding proteins present in the ER membrane [84]. Genes that localize to the ER in hypoxia for translation include VEGF, HIF1 and P4HA1 [77]. The localization of specific mRNA, including HIF target genes, to the ER in response to hypoxia further contributes to hypoxia-specific proteomic adaptations.

Selective hypoxia-responsive mRNA translation also occurs by the direct binding of the ribosome to internal ribosome entry sites (IRES). IRES are short sequences at the mRNA 5'UTR that promote ribosome recruitment without cap-binding translation initiation machinery $[85,86]$. IRES vary in sequence among different genes and are also proposed to fold into secondary structures that promote ribosomal recruitment and binding [87]. IRES are mainly found in viral mRNA though some eukaryotic genes also harbor this sequence for selective translation initiation in response to stress, including hypoxia. Some genes known to utilize IRES-dependent translation in hypoxia include VEGF [88], human fibroblast growth factors $(F G F)$ [89], insulin-like growth factors (IGFs) [90], eIF4G [91], platelet-derived growth factors (PDGF) [92] and proto-oncogene C-MYC [87, 93, 94].
While IRES-mediated protein synthesis is active and may partially explain the specificity of mRNA translated in hypoxia, IRES-mediated protein synthesis accounts for less than $1 \%$ of the level of cap-binding dependent mRNA-to-protein translation in hypoxia, a prevalence that is likely too low for cell survival [94]. Hence, IRES-mediated mRNA-to-protein translation is not sufficient to account for all translated proteins in hypoxia and an alternate pathway must exist.

While these mechanisms of mRNA selection for translation do not change in hypoxia compared to normoxia, genes containing uORFs or IRES regions in the mRNA rely on hypoxia for translation initiation. They are crucial to contributing to proteomic changes that mediate cellular response to hypoxia by selecting mRNA for translation initiation.

\section{Translation initiation}

In normoxia, mRNA-to-protein translation initiation is a concerted process involving mRNA activation by eukaryotic initiation factors (eIFs) and pre-initiation complex (PIC) recruitment. PIC consists of the $40 \mathrm{~S}$ small ribosome subunit and an initiation tRNA charged with methionine (met-tRNA ${ }_{\mathrm{i}}$ ) that recognizes the AUG start codon in the mRNA. PIC formation is catalyzed by eIF1, eIF1A, eIF2, eIF3 and eIF5. eIF1 and eIF1A are responsible for inducing an "open" conformational change to the $40 \mathrm{~S}$ ribosome subunit to prevent the met-tRNA $\mathrm{i}_{\mathrm{i}}$ from binding to the A-site and promote its binding to the P-site [95]. eIF2 is a GTPase that forms a ternary complex with the met-tRNA $A_{i}$ and GTP [96]. eIF2 consists of three subunits, eIF $2 \alpha$, eIF $2 \beta$ and eIF2 $\gamma$ [96]. eIF2 $\alpha$ contains a regulatory region in which ser ${ }^{51}$ phosphorylation regulates function. eIF2 $\gamma$ binds to GTP and hydrolyses the nucleotide to GDP. eIF2 $\beta$ mediates the exchange of GDP for a new GTP, promoting ternary complex formation and interacts with other initiation factors and the mRNA. eIF2 is active when eIF2 $\alpha$ is not phosphorylated at $\operatorname{ser}^{51}$, as is the case in normoxia. In hypoxia, eIF $2 \alpha$ is phosphorylated by kinases such as protein kinase $\mathrm{R}$ (PKR)-like endoplasmic reticulum kinase (PERK) [96].

PERK is an endoplasmic reticular kinase that "monitors" cell homeostasis by sensing ER stress and stress-induced protein unfolding in the ER, initiating the unfolded protein response (UPR) in cells. When activated, PERK ultimately inhibits global mRNA-to-protein translation [97]. While inactive in normoxia, PERK is hyperphosphorylated in hypoxia, which phosphorylates eIF2 $\alpha$. Phosphorylated eIF2 $\alpha$ inhibits eIF2 GTPase function and prevents the ternary complex formation and recruitment of met-tRNA $A_{i}$ to the $40 \mathrm{~S}$ ribosome and $43 \mathrm{~S}$ PIC formation [96, 97]. PERK activation in the UPR pathway promotes preferential translation of mRNA that 
encode stress-responsive factors to restore cellular homeostasis [98]. This ultimately inhibits mRNA capbinding in mRNA-to-protein translation initiation, promoting energy conservation and redirection of the energy conserved in cells to increase expression of cell survival genes. Interestingly, a rapid increase of eIF $2 \alpha$ phosphorylation occurs in acute hypoxia but is reversed in prolonged hypoxia exposures [99]. eIF2 $\alpha$ may slowly be de-phosphorylated and may become active in chronic hypoxia to mediate long-term adaptation and survival in hypoxia.

In parallel to PIC formation in normoxia, the mRNA translation is activated by eIF4E binding. eIF4E is a protein in the eIF4F complex that recognizes and binds to the 7-methyl-guanine cap structure at the $5^{\prime}$ end of the mRNA [100]. The eIF4F complex also consists of eIF4A and eIF4G proteins which remove mRNA secondary structures to allow for more conducive PIC binding to the $5^{\prime}$ end of the mRNA. eIF4G also binds to a poly-(A) binding protein (PABP), which associates with the 3' poly-adenylated mRNA tail end. This was initially thought to cause the mRNA to fold into a loop structure [101-103]. However, recent research show that few mRNAs actually form this "closed-loop structure"; rather, mRNA bound to the eIF4F complex and not PABP form the loop structure, while mRNA bound to PABP, which consist of most mRNAs, do not [104, 105]. Further elucidation regarding the use of the "closed-loop structure" of mRNA in translation will be necessary. The eIF4F complex recruits the pre-assembled PIC to the $5^{\prime}$ end of the mRNA, forming the $48 \mathrm{~S}$ ribosome-mRNA complex [106]. PIC scans the mRNA from the $5^{\prime}$ end to the $3^{\prime}$ end until the met-tRNA $A_{i}$ identifies and binds to the AUG start codon. Met-tRNA $A_{i}$ binding to the start codon causes eIF2 hydroxylation, which releases eIF proteins from the $48 \mathrm{~S}$ complex and promotes the binding of the 60S large ribosome subunit to initiate translation elongation [107].

Cap-dependent translation initiation is regulated by mammalian target of rapamycin (mTOR) [108, 109]. mTOR is a protein kinase that phosphorylates target protein serine/threonine residues to ultimately promote cellular growth, proliferation and survival [109]. One mTOR complex 1 (mTORC1) target protein is the mRNA-to-protein translation repressor $4 \mathrm{E}$ binding protein (4E-BP), which sequesters eIF4E upon activation. 4E-BP phosphorylation by mTORC1 in normoxia allows eIF4E to bind to other initiation factors to begin protein synthesis [108]. While the mTORC1 pathway may be overactive in cancers, leading to dysregulated cell cycles and proliferation, hypoxia inhibits mTOR activity via REDD1 and AMPK activation [110, 111]. mTORC1 inhibition in hypoxia leads to the de-phosphorylation and activation of $4 \mathrm{E}-\mathrm{BP}$ to continually sequester eIF4E
[108, 109]. Hence, mTORC1 inactivation in hypoxia inhibits eIF4E at the translation initiation step. This has the effect of decreasing global mRNA-to-protein translation rate.

However, cells must continue to generate proteins that promote survival and adaptation under hypoxic stress. With the inhibition of mTORC1-mediated canonical translation mechanisms, cells activate alternative translation pathways that first begin with selective mRNA recruitment and translation initiation.

To provide insight into this seeming paradox of active mRNA-to-protein synthesis in hypoxia, Uniacke et al. discovered that HIF $2 \alpha$ not only functions as a transcription factor in hypoxia, but also functions as a cap-dependent translation initiation factor in the absence of oxygen (Fig. 3) [22]. Hypoxia promotes the formation of a translation initiation complex that includes HIF2 $\alpha$, RNA-binding protein RBM4 and eIF4E2 [22]. The complex is assembled at the 3'UTR of the mRNA by recognition of a hypoxia response element (rHRE), identified as the sequence $\mathrm{CG}(\mathrm{G})$. RBM4 is first recruited to the rHRE, followed by HIF2 $\alpha$ and eIF4E2, a homolog of eIF4E. The RBM4/HIF $2 \alpha /$ eIF4E2 complex on the 3'UTR then interacts with the mRNA 5'cap [22].The complex binds to other initiation factors, namely eIF4A and eIF4G3, forming the eIF4F $\mathrm{F}^{\mathrm{H}}$ complex, which recruits ribosomes for translation [22, 112]. Cells appear to form the eIF4F $\mathrm{F}^{\mathrm{H}}$ complex only for hypoxic translation initiation; when RBM4, HIF2 $\alpha$ or eIF4E2 are knocked down, the hypoxic cells are less viable. However, when one of those factors are inhibited in normoxic cells, no changes in global protein synthesis were observed $[22,112]$. The discovery that hypoxic cells utilize a separate cap-dependent, oxygen-independent translation initiation mechanism has implications for hypoxic-specific cancer therapies.

Three different classes of mRNA appear in the hypoxia framework: class I consists of genes that are downregulated in hypoxia compared to normoxia; class II genes are oxygen-independently expressed genes and are not affected by hypoxia; and class III consists of genes that are upregulated in hypoxia [75]. Class III genes may be preferentially expressed in hypoxia due to the presence of the rHRE region in the mRNA that recruits the eIF4 $\mathrm{F}^{\mathrm{H}}$ complex to initiate cap-dependent translation [75]. Because only select gene mRNA transcripts contain the rHRE element, its role in recruiting the eIF $4 \mathrm{~F}^{\mathrm{H}}$ complex to initiate translation significantly contributes to the specificity of protein expression in hypoxia. eIF4 $\mathrm{F}^{\mathrm{H}}$ complex may mediate a major pathway for hypoxic protein synthesis pathway analogous to the normoxic eIF4F complex.

\section{Translation elongation}

In normoxia, protein elongation is mediated by eukaryotic elongation factors (EFs). To begin the elongation step of 


\section{Normoxia}

\section{Hypoxia}

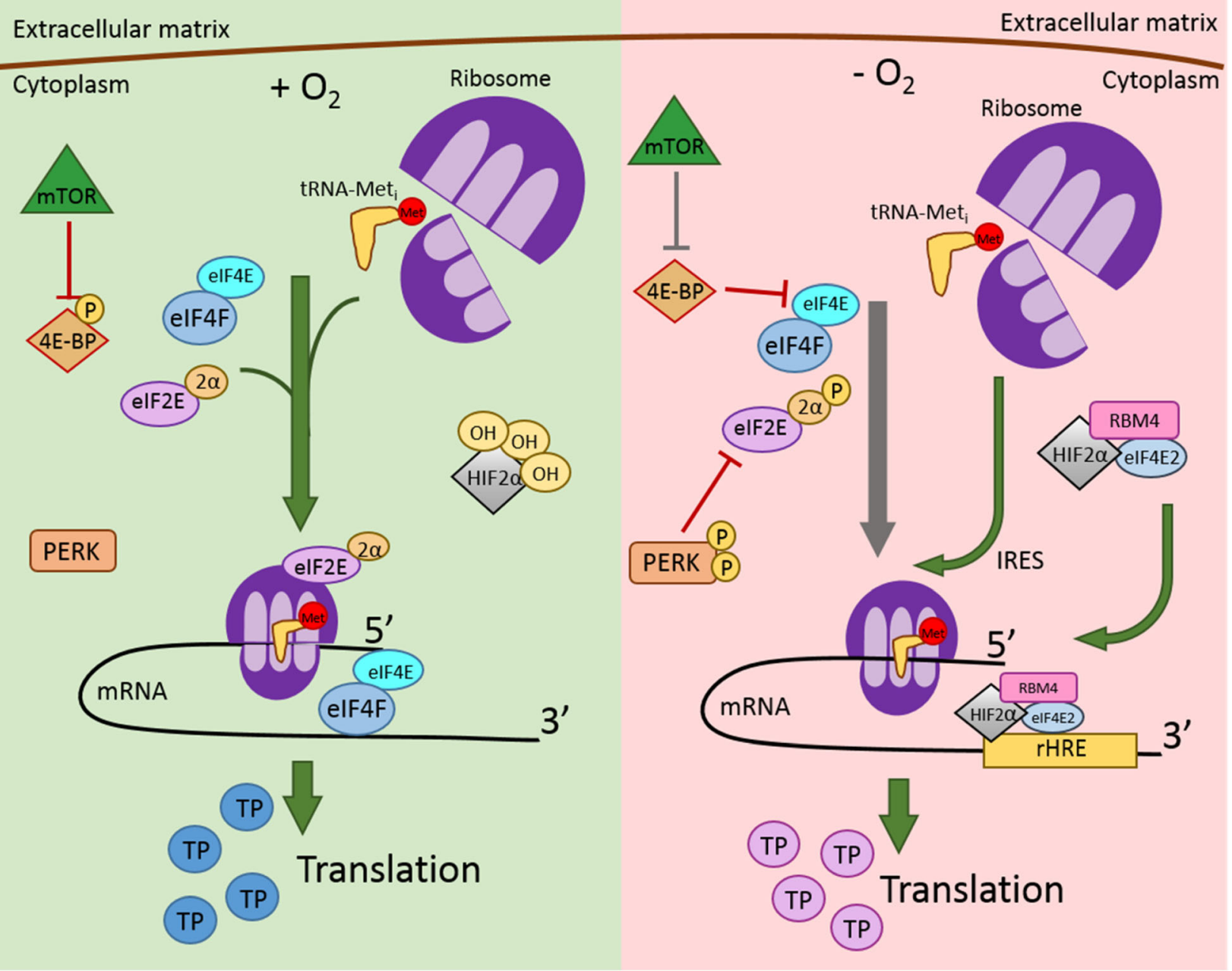

Extracellular matrix

Fig. 3 mRNA-to-protein translation initiation in normoxia and hypoxia. tRNA-Meti: transfer ribonucleic acid charged with initiation methionine; Met: methionine; elF4E: eukaryotic initiation factor 4E; elF4F: eukaryotic initiation factor complex 4F; elF2E: eukaryotic initiation factor 2E; 2a: eukaryotic initiation factor 2 subunit a; mTOR: mammalian target of rapamycin; O2: oxygen; 4E-BP: eukaryotic initiation factor 4E binding protein; P: phosphate; PERK: protein kinase R (PKR)-like endoplasmic reticulum kinase; HIF2a: hypoxia-inducible factor 2a; OH: hydroxyl group; mRNA: messenger ribonucleic acid; TP: target protein; RBM4: RNA binding motif protein 4; elF4E2: eukaryotic initiation factor 4E2; rHRE: RNA hypoxia response element

mRNA-to-protein translation, eEF1A, a GTPase, binds to a GTP and an amino acid-bound tRNA (charged tRNA). This complex moves into the " $\mathrm{A}$ " site of the ribosome while the "P" site is occupied by the met-tRNA $A_{i}$ from the translation initiation step. If the charged tRNA anticodon in the "A" site matches the codon on the mRNA, eEF1A hydrolyzes the GTP and departs the complex, allowing the peptide bond to form between the charged tRNA in the "P" site and the incoming amino acid-tRNA in the " $\mathrm{A}$ " site. Upon peptide bond formation, the tRNA in the "A" site with the growing peptide bond will move to the "P" site. This movement is mediated by another elongation factor eEF2, a GTPase that translocate the tRNA from the "A" site to the subsequent position in the ribosome upon GTP hydrolysis. When the tRNA is in the correct "P" site, eEF2 releases from the " $A$ " site of the ribosome, leaving it vacant for the next tRNA to match the following codon on the mRNA. In this process, eEF2 appears to be the only protein differentially regulated in hypoxia.

The rate of mRNA-to-protein translation elongation is regulated by eEF2 kinase (eEF2K). eEF2K is a unique calcium/calmodulin-binding kinase that regulates eEF2. eEF2K, when activated, phosphorylates and inhibits eEF2 activity thus inhibiting protein elongation when the cell 
is under stress [113]. The decreased rate of translation elongation may be imperative for cell survival since it allows cells to conserve energy and redirect the limited energy. In hypoxia, eEF2K is activated and phosphorylates eEF2, decreasing protein elongation rates [113, 114].

eEF2K activity is regulated by the binding of calcium/ calmodulin complex and by proline hydroxylation. Under cell stress, the interaction between eEF2K and calcium/calmodulin facilitates eEF2K(thr ${ }^{348}$ ) autophosphorylation. The activated eEF2K then phosphorylates eEF2 $\left(\right.$ thr $^{56}$ ), inactivating the elongation factor and inhibiting translation elongation. It was initially believed that mTORC1 was the sole regulator of eEF2K in hypoxia that resulted in translation elongation downregulation [114]. However, eEF2K is also regulated by prolyl hydroxylation by prolyl hydroxylase 2 ( $\mathrm{PH} 2)$, a member of the PHD enzyme family [113]. In normoxia, $\mathrm{PH} 2$ uses oxygen as a co-substrate to hydroxylate eEF2K $\left(\right.$ pro $^{98}$ ), preventing protein activation. This allows for eEF2 to remain unphosphorylated allowing translation elongation. In hypoxia, however, $\mathrm{PH} 2$ activity in eEF2K regulation is impaired due to the lack of oxygen co-substrate, allowing eEF2K to bind to calcium/calmodulin and leading to eEF2 phosphorylation and inactivation, decreasing the rate of global protein synthesis [113, 115-119].

It is well established that global mRNA-to-protein translation elongation rates are significantly decreased due to eEF2 inhibition by eEF2K activation in hypoxia [22]. However, the mechanism in which translation elongation occurs in hypoxia despite eEF2 inhibition remains unknown. It will be interesting to find out how hypoxic cells accomplish translation elongation when the mechanism is eventually discovered.

\section{Translation termination}

mRNA-to-protein translation is terminated by release factors 1 and 3 (eRF1 and eRF3). eRF1 is a structural homolog of tRNAs, consisting of a codon binding site that recognizes the three stop codons: UAA, UGA and UAG. At the end of translation elongation, the ribosome shifts down the mRNA to the stop codon. An incoming eRF1 enters the A site and binds to the stop codon, promoting the recruitment of eRF3, a GTPase that binds to eRF1. eRF3 then hydrolyzes the end of the polypeptide chain protruding from the $\mathrm{P}$ site. This hydrolysis releases the newly synthesized protein from the ribosome and allows dissociation of the ribosome and mRNA complex [120].

The rate of translation termination is controlled by posttranslational modifications of eRF1. eRF1 contains a highly conserved Asparagine-Isoleucine-Lysine-Serine (NIKS) sequence at the N-terminus that is hydroxylated by an oxygenase Jumonji domain-containing 4 (Jmjd4) $[121,122]$. eRF1 hydroxylation is required for optimal translation termination rates in normoxia. In hypoxia, eRF1 hydroxylation is decreased, inhibiting stop codon recognition by eRF1 and promoting more incidents of readthrough $[121,123]$. Ribosomal readthrough has been observed in response to oxygen and glucose deprivation, resulting in the translation of target protein isoforms [124]. While the functions of these protein isoforms translated in hypoxia are largely unknown, subunits or domains that contribute to hypoxic protein regulation and activation may exist in the additional protein sequence that confer differential regulation in hypoxia.

\section{HIF inhibitors as potential therapeutics}

Modulating HIF activity is an area of interest in many different diseases including anemia, ischemia and cancer. In treating anemia and ischemia, increased HIF activity is favorable and patients are administered PHD inhibitors or HIF stabilizers, such as vadadustat, to increase HIF expression [125, 126]. Vadadustat is an investigational drug in Phase III trials to treat anemia. It that works by increasing HIF activity and consequently increasing erythropoietin and red blood cell production [127]. While HIFs play an integral role in cell survival under hypoxic stress, their dysregulation may result in cancer development and progression. In healthy cells, HIF $1 \alpha$ expression is generally higher than HIF $2 \alpha$ expression, except for in the pancreas, liver and kidneys. However, this relatively conserved HIF $1 \alpha$-to-HIF2 $\alpha$ expression ratio is significantly higher or lower in many malignant solid tumors that express either more HIF1 $\alpha$ or HIF $2 \alpha$ than in normoxia. This imbalance is indicative of poor prognosis in patients $[25,26]$. Targeting HIFs in cancers has been a growing area of interest that has entered the realm of clinical trials in the past decade, with some therapies showing potential, but none having yet received regulatory approval.

One major HIF1 $\alpha$-targeting small molecule inhibitor, PX-478, has demonstrated potent antitumorigenic effects [128]. It was found to significantly decrease HIF1 $\alpha$ mRNA and protein levels by blocking its transcription and translation [128]. Furthermore, PX-478 treated cells have decreased rates of HIF1 $\alpha$ de-ubiquitination, resulting in higher HIF1 $\alpha$ degradation [128]. HIF1 $\alpha$ target gene expression also decreased. In another study, PX-478 re-sensitized prostate carcinoma cells to radiation therapy [129]. PX-478 has undergone Phase I clinical trials for the treatment of advanced solid tumors or lymphomas and considering the positive results, the drug remains of interest for further evaluation as a cancer therapeutic [130].

Hypoxia-activated prodrugs are currently in development for clinical use. The benefit of hypoxia-activated prodrugs is the selectivity in targeting hypoxic cancer cells. One such prodrug is Evofosfamide (TH-302) has been proven to be especially effective in targeting cancer 
cells. Evofosfamide is a 2-nitroimidazole prodrug that undergoes a single electron reduction, resulting in a radical anion prodrug that immediately reacts with oxygen present in the environment [131]. This reaction reverts the anion prodrug back to the original state of Evofosfamide. In hypoxia, there is no oxygen molecules to interact with the anion prodrug, resulting in the fragmentation of the anion prodrug that results in the active alkylating cytotoxic agent [131]. This agent crosslinks DNA thus inhibiting replication. Due to the highly selective and potent effect of this drug on hypoxic cells, it has been used in Phase II clinical trials in combination with Bortezomib, a standard chemotherapeutic, in targeting hypoxic cancers in patients with relapsed myeloma [132]. The results show that the treatment combination was well tolerated in patients with modest efficacy [132].

While prodrugs may seem promising, the use of small molecules to target hypoxic cancer cells nevertheless appears to be effective. For example, the use of topotecan and other topoisomerase I inhibitors have been used to treat cancers in the clinic. The effect that topotecan has on hypoxia has been studied in clinical trials [133]. In 2011, the inhibitory effects of topotecan on HIF1 $\alpha$ activity were evaluated in 22 patients [133]. Topotecan inhibits HIF $1 \alpha$ by a mechanism independent of its role in DNA replication [133-135]. However, results showed no exclusive correlation between HIF target gene expression and topotecan treatment in patient cancer cells. While HIF expression and activity decreased in patients treated with topotecan, the expression of the HIF target gene VEGF was unchanged [133]. The results of this study did not suggest topotecan as a HIF-targeting cancer therapeutic due to its short plasma half-life of $\sim 3 \mathrm{~h}$, lack of HIF specificity and high toxicity $[133,136]$.

In 2016, the idea of using a nanoparticle conjugate CRLX101 with the administration of an anti-angiogenesis antibody bevacizumab to target hypoxic cancer cells was explored in a Phase I clinical trial [137]. The CRLX101 nanoparticle-drug conjugate is infused with a topotecan analog camptothecin, another topoisomerase I inhibitor. Camptothecin decreases HIF protein transcription, effectively decreasing its activity in hypoxic cells [137]. The reasons for using nanoparticle-drug conjugate to deliver camptothecin is two-fold. First, nanoparticles appear to preferentially aggregate into tumor cells, allowing for increased specificity in targeting cancer cells [137]. Second, the nanoparticle conjugate allows for a slow release of the infused camptothecin, significantly increasing the half-life of the drug [137]. Camptothecin also displays less toxicity compared to topotecan and is better tolerated by patients. The nanoparticle-drug conjugate CRLX101 is currently in several preclinical studies and Phase I and Phase II clinical trials for the treatment of gastroesophageal cancer, advanced renal cell carcinoma and breast cancer [138-141].
The effect that camptothecin has on hypoxic protein synthesis has not yet been studied.

There are also compounds that specifically target HIF2 $\alpha$ activity, such as PT2385 and PT2399. PT2385 and PT2399 are both small-molecule antagonists that block the dimerization of HIF2 $\alpha$ with ARNT by directly binding to the PAS domain of HIF2 $\alpha$, inhibiting the transcription of HIF $2 \alpha$ target genes [142, 143]. The role of these small molecule inhibitors on HIF $2 \alpha$-mediated translation remain unreported. When tumor xenografts were treated with PT2385 in mice, HIF2 $\alpha$ target gene expression significantly decreased in vitro and in vivo and HIF $2 \alpha$ mRNA and protein expression levels also decreased in vivo. As a result, PT2385 treated tumor xenografts showed tumor regression, reduced angiogenesis, lower rates of cell proliferation and increased apoptosis. Based on the promising in vitro and in vivo studies, PT2385 was the first HIF2 $\alpha$ antagonist to enter clinical trials and is currently in Phase II. While HIF $2 \alpha$ transcriptional activity and expression levels is inhibited by PT2385, the effect of the drug on HIF2 $\alpha$ translational role in hypoxia remains to be studied.

Another method of targeting hypoxic cancer cells is by inhibiting eIF4E2 activity. eIF4E2 is active only in hypoxia and complexes with HIF2 $\alpha /$ RBM4 to initiate the first step of hypoxic translation [112]. By inhibiting eIF4E2, and consequently inhibiting hypoxic protein synthesis, cancer cells can be distinctively targeted from healthy cells by inhibiting the hypoxic protein synthesis pathway. Evidence suggests that eIF4E2 suppression significantly slows or even reverses cancer growth [112]. While an eIF4E2 targeting drug has immense potential as a cancer therapy, there has been difficulty finding a compound that can distinctively target eIF4E2 over eIF4E. There are currently therapies targeting eIF4E, such as the use of antisense oligonucleotides and small molecule inhibitors that block eIF4E complexing with eIF4G [144-146]. However, because these targeting methods cannot effectively distinguish eIF4E2 from eIF4E, healthy cells that utilize the cap-dependent translation initiation will also become the target of these therapies. Therefore, there is still a need to identify a cancer therapy that specifically targets eIF4E2 to inhibit protein synthesis in hypoxic cancer cells.

Targeting HIFs specifically in cancer cells may present an insurmountable challenge. Although a major hallmark in cancers, HIFs also have important roles in normal physiology and function of different tissues, such as normal kidney and liver which utilize hypoxia and the activation of HIF pathways to maintain homeostasis. Targeting HIFs, therefore, may inevitably lead to intolerably severe side effects. Furthermore, many HIF inhibitors target both HIF1 $\alpha$ and HIF2 $\alpha$ or are mechanistically aimed at inhibiting HIF transcriptional activity [22]. 
Developing a HIF2 $\alpha$-mediated translation specific inhibitor holds some potential to differentiate from currently available inhibitors. However, the lack of useful compounds targeting HIF2 $\alpha$-mediated translation makes it difficult to answers these questions.

\section{Summary}

Cell stress initiated by a hypoxic environment necessitates intricate orchestration and reorganization of cellular homeostasis in order to adapt and survive such a harsh insult. While it is well known that the transcriptional landscape of the cell is changed, it is becoming clearer that hypoxic protein synthesis is also fine-tuned by oxygendependent proteins, such as HIFs and PHDs. Targeting hypoxic translational activity holds significant potential for the treatment of cancer, perhaps even more than targeting transcriptional activity due to the unique machinery cells use in protein synthesis for hypoxia adaptation.

\section{Abbreviations}

4E-BP: Eukaryotic initiation factor 4E binding protein; AMPK: 5' adnosine monophosphate activated protein kinase; ARNT: Aryl hydrocarbon receptor nuclear translocator; ATP: Adenosine triphosphate; bHLH: Basic helix-loophelix; CBP: CREB-binding protein; Cdk1: Cyclin dependent kinase 1; Cdk2: Cyclin dependent kinase 2; C-MYC: Cancer myelocytomatosis gene; CTAD: C-terminal transactivation domain; CXCR4: CXC chemokine receptor type 4; eEFs: Eukaryotic elongation factors; elFs : Eukaryotic initiation factors; EPO: Erythropoietin; eRFs: Eukaryotic release factors; FDA: Food and Drug Administration; FGF: Fibroblast growth factor; FlH: Factor inhibiting Hypoxiainducible factor; GADD34: Protein phosphatase 1 regulatory subunit 15A; also known as PPP1R15A; GDP: Guanine diphosphate; GLUT1: Glucose transporter 1; GTP: Guanine triphosphate; GTPase: Guanine triphosphatase; HIF: Hypoxiainducible factor; HIFalpha: Hypoxia-inducible factor subunit alpha; HIFbeta: Hypoxia-inducible factor subunit beta; HIF-PH2: Hypoxia-inducible factor prolyl hydroxylase 2; HRE: Hypoxia response element; IGF: Insulin-like growth factor; IRES: Internal ribosome entry site; Jmjd4: Jumonji domaincontaining 4; LC3C: Microtubule-associated proteins 1A/1B light chain 3C; also known as MAP1LC3C; LDH: Lactate dehydrogenase; mAUG: Main AUG; met-tRNAi: Methionine charged transfer ribonucleic acid; mORF: Main open reading frame; mRNA: Messenger ribonucleic acid; mTOR: Mammalian target of rapamycin; NIKS: Asparagine-Isoleucine-Lysine-Serine; N-TAD: N-terminal transactivation domain; OCT4: Octamer-binding transcription factor 4; ODDD: Oxygen dependent degradation domain; p300: E1A-associated protein 300; P4HA1: Proyly 4-hyroxylase subunit Alpha 1; PABP: Poly(A)binding protein; PAS: Per-Arnt-Sim; Period circadian protein-aryl hydrocarbon receptor nuclear translocator protein-single-minded protein; PDGF: Plateletderived growth factor; PERK: Protein kinase R (PKR)-like endoplasmic reticulum kinase; PHD: Prolyl hydroxylase domain; PIC: Pre-initiation complex; pO2: Oxygen gas partial pressure; pVHL-E3: von-Hippel Lindau tumor suppressor, E3 ubiquitin ligase complex; REDD1: DNA damage inducible transcript 4; also known as DDIT4; rHRE: Ribonucleic acid hypoxia response element; RMB4: RNA binding motif protein 4; SQRDL: Sulfide quinone reductase-like; SRP: Signal recognition particle; tRNA : Transfer ribonucleic acid; UAUG: Upstream AUG; UORF: Upstream open reading frame; UTR: Untranslated region; VEGF: Vascular endothelial growth factor

\section{Acknowledgements}

Not applicable.

\section{Funding}

SPB receives support from the National Institutes of Health (R01NS092671 and R01MH1 10441), the University of Miami Sylvester Comprehensive Cancer Center Molecular Therapeutics Shared Resource (MTSR), the Jay Weiss Institute for Health Equity and the Ryan Foundation.
Availability of data and materials

Not applicable.

\section{Authors' contributions}

All authors contributed to the writing of the manuscript. All authors read and approved the final manuscript.

Ethics approval and consent to participate

Not applicable.

\section{Consent for publication}

All authors consent.

\section{Competing interests}

The authors declare that they have no competing interest.

\section{Publisher's Note}

Springer Nature remains neutral with regard to jurisdictional claims in published maps and institutional affiliations.

Received: 15 October 2018 Accepted: 21 February 2019

Published online: 30 March 2019

References

1. Carreau A, Hafny-Rahbi BE, Matejuk A, Grillon C, Kieda C. Why is the partial oxygen pressure of human tissues a crucial parameter? Small molecules and hypoxia. J Cell Mol Med. 2011;15:1239-53.

2. Patel $\mathrm{D}$, Alhawaj R, Wolin MS. Exposure of mice to chronic hypoxia attenuates pulmonary arterial contractile responses to acute hypoxia by increases in extracellular hydrogen peroxide. Am J Physiol Regul Integr Comp Physiol. 2014;307:R426-33.

3. Masson N, Ratcliffe PJ. Hypoxia signaling pathways in cancer metabolism: the importance of co-selecting interconnected physiological pathways. Cancer Metab. 2014;2:3.

4. Martin JD, Fukumura D, Duda DG, Boucher Y, Jain RK. Reengineering the tumor microenvironment to alleviate hypoxia and overcome Cancer heterogeneity. Cold Spring Harbor perspectives in medicine. 2016;6:a027094.

5. Wein F, Otto T, Lambertz P, Fandrey J, Hansmann ML, Kuppers R. Potential role of hypoxia in early stages of Hodgkin lymphoma pathogenesis. Haematologica. 2015;100:1320-6.

6. Bhalla K, Jaber S, Nahid MN, Underwood K, Beheshti A, Landon A, Bhandary B, Bastian P, Evens AM, Haley J, et al. Role of hypoxia in diffuse large B-cell lymphoma: metabolic repression and selective translation of HK2 facilitates development of DLBCL. Sci Rep. 2018:8:744.

7. Szymczak D, Dybko J, Kuliczkowski K. The role of hypoxia-inducible factors in leukemias. Adv Clin Exp Med. 2018;27:271-5.

8. van Oosterwijk JG, Buelow DR, Drenberg CD, Vasilyeva A, Li L, Shi L, Wang $Y D$, Finkelstein D, Shurtleff SA, Janke LJ, et al. Hypoxia-induced upregulation of BMX kinase mediates therapeutic resistance in acute myeloid leukemia. J Clin Invest. 2018;128:369-80.

9. Schaaf MB, Garg AD, Agostinis P. Defining the role of the tumor vasculature in antitumor immunity and immunotherapy. Cell Death Dis. 2018:9:115.

10. Labiano S, Palazon A, Melero I. Immune response regulation in the tumor microenvironment by hypoxia. Semin Oncol. 2015;42:378-86.

11. Zhang C, Samanta D, Lu H, Bullen JW, Zhang H, Chen I, He X, Semenza GL. Hypoxia induces the breast cancer stem cell phenotype by HIF-dependent and ALKBH5-mediated m(6)A-demethylation of NANOG mRNA. Proc Natl Acad Sci U S A. 2016;113:E2047-56.

12. Covello KL, Kehler J, Yu H, Gordan JD, Arsham AM, Hu CJ, Labosky PA, Simon MC, Keith B. HIF-2alpha regulates Oct-4: effects of hypoxia on stem cell function, embryonic development, and tumor growth. Genes Dev. 2006; 20:557-70.

13. Takubo K, Goda N, Yamada W, Iriuchishima H, Ikeda E, Kubota Y, Shima H, Johnson RS, Hirao A, Suematsu M, Suda T. Regulation of the HIF-1alpha level is essential for hematopoietic stem cells. Cell Stem Cell. 2010;7:391-402.

14. Warfel NA, El-Deiry WS. HIF-1 signaling in drug resistance to chemotherapy. Curr Med Chem. 2014;21:3021-8.

15. Rankin EB, Higgins DF, Walisser JA, Johnson RS, Bradfield CA, Haase VH. Inactivation of the arylhydrocarbon receptor nuclear translocator (Arnt) suppresses von Hippel-Lindau disease-associated vascular tumors in mice. Mol Cell Biol. 2005;25:3163-72. 
16. Tang N, Wang L, Esko J, Giordano FJ, Huang Y, Gerber HP, Ferrara N, Johnson RS. Loss of HIF-1alpha in endothelial cells disrupts a hypoxiadriven VEGF autocrine loop necessary for tumorigenesis. Cancer Cell. 2004;6:485-95.

17. Yan Q, Bartz S, Mao M, Li L, Kaelin WG Jr. The hypoxia-inducible factor 2alpha N-terminal and C-terminal transactivation domains cooperate to promote renal tumorigenesis in vivo. Mol Cell Biol. 2007;27:2092-102.

18. Wang Z, Da Silva TG, Jin K, Han X, Ranganathan P, Zhu X, Sanchez-Mejias A, Bai $F$, Li B, Fei DL, et al. Notch signaling drives stemness and tumorigenicity of esophageal adenocarcinoma. Cancer Res. 2014;74:6364-74.

19. Osman NA, Abd El-Rehim DM, Kamal IM. Defective Beclin-1 and elevated hypoxia-inducible factor (HIF)-1alpha expression are closely linked to tumorigenesis, differentiation, and progression of hepatocellular carcinoma. Tumour Biol. 2015;36:4293-9.

20. Kafri M, Metzl-Raz E, Jona G, Barkai N. The cost of protein production. Cell Rep. 2016;14:22-31.

21. Liu L, Cash TP, Jones RG, Keith B, Thompson CB, Simon MC. Hypoxiainduced energy stress regulates mRNA translation and cell growth. Mol Cell. 2006;21:521-31.

22. Uniacke J, Holterman CE, Lachance G, Franovic A, Jacob MD, Fabian MR, Payette J, Holcik M, Pause A, Lee S. An oxygen-regulated switch in the protein synthesis machinery. Nature. 2012;486:126-9.

23. Holmquist-Mengelbier L, Fredlund E, Lofstedt T, Noguera R, Navarro S, Nilsson H, Pietras A, Vallon-Christersson J, Borg A, Gradin K, et al. Recruitment of HIF-1alpha and HIF-2alpha to common target genes is differentially regulated in neuroblastoma: HIF-2alpha promotes an aggressive phenotype. Cancer Cell. 2006;10:413-23.

24. Koh MY, Lemos R, Liu X, Powis G. The hypoxia-associated factor switches cells from HIF-1a- to HIF-2a-dependent signaling promoting stem cell characteristics, aggressive tumor growth and invasion. Cancer Res. 2011;71:4015-27

25. Wiesener MS, Jurgensen JS, Rosenberger C, Scholze CK, Horstrup JH, Warnecke C, Mandriota S, Bechmann I, Frei UA, Pugh CW, et al. Widespread hypoxia-inducible expression of HIF-2alpha in distinct cell populations of different organs. FASEB J. 2003;17:271-3.

26. Talks KL, Turley H, Gatter KC, Maxwell PH, Pugh CW, Ratcliffe PJ, Harris AL. The expression and distribution of the hypoxia-inducible factors HIF-1a and HIF-2a in Normal human tissues, cancers, and tumor-associated macrophages. Am J Pathol. 2000;157:411-21.

27. Makino Y, Cao R, Svensson K, Bertilsson G, Asman M, Tanaka H, Cao Y, Berkenstam A, Poellinger L. Inhibitory PAS domain protein is a negative regulator of hypoxia-inducible gene expression. Nature. 2001;414:550-4.

28. Chapman-Smith A, Lutwyche JK, Whitelaw ML. Contribution of the per/ Arnt/Sim (PAS) domains to DNA binding by the basic helix-loop-helix PAS transcriptional regulators. J Biol Chem. 2004;279:5353-62.

29. Hu CJ, Sataur A, Wang L, Chen H, Simon MC. The N-terminal transactivation domain confers target gene specificity of hypoxia-inducible factors HIF1alpha and HIF-2alpha. Mol Biol Cell. 2007;18:4528-42.

30. Wang GL, Jiang BH, Rue EA, Semenza GL. Hypoxia-inducible factor 1 is a basic-helix-loop-helix-PAS heterodimer regulated by cellular $\mathrm{O} 2$ tension. Proc Natl Acad Sci U S A. 1995;92:5510-4.

31. Semenza GL, Agani F, Booth G, Forsythe J, lyer N, Jiang BH, Leung S, Roe R, Wiener C, Yu A. Structural and functional analysis of hypoxia-inducible factor 1. Kidney Int. 1997;51:553-5.

32. Huang LE, Gu J, Schau M, Bunn HF. Regulation of hypoxia-inducible factor $1 \mathrm{a}$ is mediated by an O(2)-dependent degradation domain via the ubiquitin-proteasome pathway. Proc Natl Acad Sci U S A. 1998;95:7987-92.

33. Hara S, Hamada J, Kobayashi C, Kondo Y, Imura N. Expression and characterization of hypoxia-inducible factor (HIF)-3alpha in human kidney: suppression of HIF-mediated gene expression by HIF-3alpha. Biochem Biophys Res Commun. 2001;287:808-13.

34. Maynard MA, Qi H, Chung J, Lee EH, Kondo Y, Hara S, Conaway RC, Conaway JW, Ohh M. Multiple splice variants of the human HIF-3 alpha locus are targets of the von Hippel-Lindau E3 ubiquitin ligase complex. J Biol Chem. 2003;278:11032-40.

35. Maynard MA, Evans AJ, Hosomi T, Hara S, Jewett MA, Ohh M. Human HIF3alpha4 is a dominant-negative regulator of HIF-1 and is down-regulated in renal cell carcinoma. FASEB J. 2005:19:1396-406.

36. Lee KH, Park JW, Chun YS. Non-hypoxic transcriptional activation of the aryl hydrocarbon receptor nuclear translocator in concert with a novel hypoxiainducible factor-1alpha isoform. Nucleic Acids Res. 2004;32:5499-511.
37. Gardella KA, Muro I, Fang G, Sarkar K, Mendez O, Wright CW. Aryl hydrocarbon receptor nuclear translocator (ARNT) isoforms control lymphoid cancer cell proliferation through differentially regulating tumor suppressor p53 activity. Oncotarget. 2016;7:10710-22.

38. Shieh JM, Shen CJ, Chang WC, Cheng HC, Chan YY, Huang WC, Chang WC, Chen BK. An increase in reactive oxygen species by deregulation of ARNT enhances chemotherapeutic drug-induced cancer cell death. PLoS One. 2014;9:e99242.

39. Scott C, Bonner J, Min D, Boughton P, Stokes R, Cha KM, Walters SN, Maslowski K, Sierro F, Grey ST, et al. Reduction of ARNT in myeloid cells causes immune suppression and delayed wound healing. Am J Physiol Cell Physiol. 2014;307:C349-57.

40. Ahmed S, Wang A, Celius T, Matthews J. Zinc finger nuclease-mediated knockout of AHR or ARNT in human breast cancer cells abolishes basal and ligand-dependent regulation of CYP1B1 and differentially affects estrogen receptor alpha transactivation. Toxicol Sci. 2014;138:89-103.

41. Wigerup C, Pahlman S, Bexell D. Therapeutic targeting of hypoxia and hypoxia-inducible factors in cancer. Pharmacol Ther. 2016;164:152-69.

42. Liu W, Shen SM, Zhao XY, Chen GQ. Targeted genes and interacting proteins of hypoxia inducible factor-1. Int J Biochem Mol Biol. 2012;3:165-78.

43. Yang SL, Wu C, Xiong ZF, Fang X. Progress on hypoxia-inducible factor-3: its structure, gene regulation and biological function (review). Mol Med Rep. 2015;12:2411-6.

44. Zhang P, Yao Q, Lu L, Li Y, Chen PJ, Duan C. Hypoxia-inducible factor 3 is an oxygen-dependent transcription activator and regulates a distinct transcriptional response to hypoxia. Cell Rep. 2014;6:1110-21.

45. Berra E, Benizri E, Ginouves A, Volmat V, Roux D, Pouyssegur J. HIF prolylhydroxylase 2 is the key oxygen sensor setting low steady-state levels of HIF-1alpha in normoxia. EMBO J. 2003;22:4082-90.

46. Kim J, So D, Shin HW, Chun YS, Park JW. HIF-1alpha upregulation due to depletion of the free ubiquitin Pool. J Korean Med Sci. 2015;30:1388-95.

47. Tian YM, Yeoh KK, Lee MK, Eriksson T, Kessler BM, Kramer HB, Edelmann MJ, Willam C, Pugh CW, Schofield CJ, Ratcliffe PJ. Differential sensitivity of hypoxia inducible factor hydroxylation sites to hypoxia and hydroxylase inhibitors. J Biol Chem. 2011;286:13041-51.

48. Dengler VL, Galbraith M, Espinosa JM. Transcriptional regulation by hypoxia inducible factors. Crit Rev Biochem Mol Biol. 2014;49:1-15.

49. Bae SH, Jeong JW, Park JA, Kim SH, Bae MK, Choi SJ, Kim KW. Sumoylation increases HIF-1alpha stability and its transcriptional activity. Biochem Biophys Res Commun. 2004;324:394-400.

50. Shao R, Zhang FP, Tian F, Anders Friberg P, Wang X, Sjoland H, Billig H. Increase of SUMO-1 expression in response to hypoxia: direct interaction with HIF-1alpha in adult mouse brain and heart in vivo. FEBS Lett. 2004;569: 293-300.

51. Sampson DA, Wang M, Matunis MJ. The small ubiquitin-like modifier-1 (SUMO-1) consensus sequence mediates Ubc9 binding and is essential for SUMO-1 modification. J Biol Chem. 2001:276:21664-9.

52. Tojo M, Matsuzaki K, Minami T, Honda Y, Yasuda H, Chiba T, Saya H, FujiiKuriyama Y, Nakao M. The aryl hydrocarbon receptor nuclear transporter is modulated by the SUMO-1 conjugation system. J Biol Chem. 2002;277:46576-85.

53. Cheng J, Kang X, Zhang S, Yeh ET. SUMO-specific protease 1 is essential for stabilization of HIF1alpha during hypoxia. Cell. 2007;131:584-95.

54. Koh MY, Nguyen V, Lemos R Jr, Darnay BG, Kiriakova G, Abdelmelek M, Ho $\mathrm{TH}$, Karam J, Monzon FA, Jonasch E, Powis G. Hypoxia-induced SUMOylation of E3 ligase HAF determines specific activation of HIF2 in clear-cell renal cell carcinoma. Cancer Res. 2015;75:316-29.

55. Yasinska IM, Sumbayev W. S-nitrosation of Cys-800 of HIF-1alpha protein activates its interaction with p300 and stimulates its transcriptional activity. FEBS Lett. 2003;549:105-9.

56. Khan M, Dhammu TS, Baarine M, Kim J, Paintlia MK, Singh I, Singh AK. GSNO promotes functional recovery in experimental TBI by stabilizing HIF-1alpha. Behav Brain Res. 2018;340:63-70.

57. Li F, Sonveaux P, Rabbani ZN, Liu S, Yan B, Huang Q, Vujaskovic Z, Dewhirst MW, Li CY. Regulation of HIF-1alpha stability through S-nitrosylation. Mol Cell. 2007;26:63-74.

58. Yang M, Ge W, Chowdhury R, Claridge TD, Kramer HB, Schmierer B, McDonough MA, Gong L, Kessler BM, Ratcliffe PJ, et al. Asparagine and aspartate hydroxylation of the cytoskeletal ankyrin family is catalyzed by factor-inhibiting hypoxia-inducible factor. J Biol Chem. 2011;286:7648-60.

59. Hubbi ME, Gilkes DM, Hu H, Kshitiz, Ahmed I, Semenza GL. Cyclindependent kinases regulate lysosomal degradation of hypoxia-inducible 
factor 1alpha to promote cell-cycle progression. Proc Natl Acad Sci U S A. 2014;111:E3325-34.

60. Lando D, Peet DJ, Whelan DA, Gorman JJ, Whitelaw ML. Asparagine hydroxylation of the HIF transactivation domain a hypoxic switch. Science. 2002;295:858-61.

61. Kosyna FK, Nagel M, Kluxen L, Kraushaar K, Depping R. The importin alpha/ beta-specific inhibitor Ivermectin affects HIF-dependent hypoxia response pathways. Biol Chem. 2015;396:1357-67.

62. Hyseni A, van der Groep P, van der Wall E, van Diest PJ. Subcellular FIH-1 expression patterns in invasive breast cancer in relation to HIF-1alpha expression. Cell Oncol (Dordr). 2011;34:565-70.

63. Xiong G, Deng L, Zhu J, Rychahou PG, Xu R. Prolyl-4-hydroxylase alpha subunit 2 promotes breast cancer progression and metastasis by regulating collagen deposition. BMC Cancer. 2014;14:1.

64. Sun W, Jelkmann W, Depping R. Prolyl-4-hydroxylase 2 enhances hypoxiainduced glioblastoma cell death by regulating the gene expression of hypoxia-inducible factor-alpha. Cell Death Dis. 2014;5:e1322.

65. Chen T, Ren Z, Ye LC, Zhou PH, Xu JM, Shi Q, Yao LQ, Zhong YS. Factor inhibiting HIF 1 alpha (FIH-1) functions as a tumor suppressor in human colorectal cancer by repressing HIF1alpha pathway. Cancer Biol Ther. 2015;16:244-52.

66. Warfel NA, Dolloff NG, Dicker DT, Malysz J, El-Deiry WS. CDK1 stabilizes HIF1a via direct phosphorylation of Ser668 to promote tumor growth. Cell Cycle. 2013;12:3689-701.

67. Bartoszewska S, Kochan K, Piotrowski A, Kamysz W, Ochocka RJ, Collawn JF, Bartoszewski R. The hypoxia-inducible miR-429 regulates hypoxia-inducible factor-1alpha expression in human endothelial cells through a negative feedback loop. FASEB J. 2015;29:1467-79.

68. Wang H, Flach H, Onizawa M, Wei L, McManus MT, Weiss A. Negative regulation of Hif1a expression and TH17 differentiation by the hypoxiaregulated microRNA miR-210. Nat Immunol. 2014;15:393-401.

69. Mimura I, Hirakawa Y, Kanki Y, Kushida N, Nakaki R, Suzuki Y, Tanaka T, Aburatani $\mathrm{H}$, Nangaku M. Novel Inc RNA regulated by HIF-1 inhibits apoptotic cell death in the renal tubular epithelial cells under hypoxia. Physiol Rep. 2017;5:e13203.

70. Zhou C, Ye L, Jiang C, Bai J, Chi Y, Zhang H. Long noncoding RNA HOTAIR, a hypoxia-inducible factor-1alpha activated driver of malignancy, enhances hypoxic cancer cell proliferation, migration, and invasion in non-small cell lung cancer. Tumour Biol. 2015;36:9179-88.

71. Shen Y, Liu Y, Sun T, Yang W. LincRNA-p21 knockdown enhances radiosensitivity of hypoxic tumor cells by reducing autophagy through HIF1/Akt/mTOR/P70S6K pathway. Exp Cell Res. 2017;358:188-98.

72. Yang F, Zhang H, Mei Y, Wu M. Reciprocal regulation of HIF-1alpha and lincRNA-p21 modulates the Warburg effect. Mol Cell. 2014;53:88-100.

73. Lerner RS, Nicchitta CV. mRNA translation is compartmentalized to the endoplasmic reticulum following physiological inhibition of cap-dependent translation. RNA. 2006;12:775-89.

74. Reid DW, Nicchitta CV. Primary role for endoplasmic reticulum-bound ribosomes in cellular translation identified by ribosome profiling. J Biol Chem. 2012;287:5518-27.

75. Ho JJD, Wang M, Audas TE, Kwon D, Carlsson SK, Timpano S, Evagelou SL, Brothers S, Gonzalgo ML, Krieger JR, et al. Systemic reprogramming of translation efficiencies on oxygen stimulus. Cell Rep. 2016;14:1293-300.

76. Reid DW, Nicchitta CV. Diversity and selectivity in mRNA translation on the endoplasmic reticulum. Nat Rev Mol Cell Biol. 2015;16:221-31.

77. Staudacher JJ, Naarmann-de Vries IS, Ujvari SJ, Klinger B, Kasim M, Benko E, Ostareck-Lederer A, Ostareck DH, Bondke Persson A, Lorenzen S, et al. Hypoxia-induced gene expression results from selective mRNA partitioning to the endoplasmic reticulum. Nucleic Acids Res. 2015;43:3219-36.

78. lacono M, Mignone F, Pesole G. UAUG and UORFs in human and rodent 5'untranslated mRNAs. Gene. 2005;349:97-105.

79. Somers J, Poyry T, Willis AE. A perspective on mammalian upstream open reading frame function. Int J Biochem Cell Biol. 2013;45:1690-700.

80. Calvo SE, Pagliarini DJ, Mootha VK. Upstream open reading frames cause widespread reduction of protein expression and are polymorphic among humans. Proc Natl Acad Sci U S A. 2009;106:7507-12.

81. Barbosa C, Romao L. Translation of the human erythropoietin transcript is regulated by an upstream open reading frame in response to hypoxia. Rna. 2014;20:594-608.

82. Lee $Y Y$, Cevallos $R C$, Jan E. An upstream open reading frame regulates translation of GADD34 during cellular stresses that induce elF2alpha phosphorylation. J Biol Chem. 2009;284:6661-73.
83. Arcondeguy T, Lacazette E, Millevoi S, Prats H, Touriol C. VEGF-A mRNA processing, stability and translation: a paradigm for intricate regulation of gene expression at the post-transcriptional level. Nucleic Acids Res. 2013;41:7997-8010.

84. Hermesh O, Jansen RP. Take the (RN)A-train: localization of mRNA to the endoplasmic reticulum. Biochim Biophys Acta. 1833;2013:2519-25.

85. Pettersson $\mathrm{G}$. What metabolite levels may be evolutionarily reached in the glycolytic pathway? Eur J Biochem. 1990;194:141-6.

86. Komar AA, Hatzoglou M. Cellular IRES-mediated translation: the war of ITAFs in pathophysiological states. Cell Cycle. 2011;10:229-40.

87. Kieft JS, Grech A, Adams P, Doudna JA. Mechanisms of internal ribosome entry in translation initiation. Cold Spring Harb Symp Quant Biol. 2001;66:277-83.

88. Stein I, Itin A, Einat P, Skaliter R, Grossman Z, Keshet E. Translation of vascular endothelial growth factor mRNA by internal ribosome entry: implications for translation under hypoxia. Mol Cell Biol. 1998;18:3112-9.

89. Vagner S, Gensac MC, Maret A, Bayard F, Amalric F, Prats H, Prats AC. Alternative translation of human fibroblast growth factor 2 mRNA occurs by internal entry of ribosomes. Mol Cell Biol. 1995;15:35-44.

90. Teerink $\mathrm{H}$, Voorma HO, Thomas AA. The human insulin-like growth factor II leader 1 contains an internal ribosomal entry site. Biochim Biophys Acta. 1995;1264:403-8.

91. Gan W, Rhoads RE. Internal initiation of translation directed by the 5'untranslated region of the mRNA for elF4G, a factor involved in the picornavirus-induced switch from cap-dependent to internal initiation. J Bio Chem. 1996;271:623-6.

92. Bernstein J, Sella O, Le SY, Elroy-Stein O. PDGF2/C-sis mRNA leader contains a differentiation-linked internal ribosomal entry site (D-IRES). J Biol Chem. 1997;272:9356-62.

93. Nanbru C, Lafon I, Audigier S, Gensac MC, Vagner S, Huez G, Prats AC Alternative translation of the proto-oncogene c-myc by an internal ribosome entry site. J Biol Chem. 1997;272:32061-6.

94. Young RM, Wang SJ, Gordan JD, Ji X, Liebhaber SA, Simon MC. Hypoxiamediated selective mRNA translation by an internal ribosome entry siteindependent mechanism. J Biol Chem. 2008;283:16309-19.

95. Mitchell SF, Lorsch JR. Should I stay or should I go? Eukaryotic translation initiation factors 1 and $1 \mathrm{~A}$ control start codon recognition. J Biol Chem. 2008;283:27345-9.

96. Koumenis C, Naczki C, Koritzinsky M, Rastani S, Diehl A, Sonenberg N, Koromilas A, Wouters BG. Regulation of protein synthesis by hypoxia via activation of the endoplasmic reticulum kinase PERK and phosphorylation of the translation initiation factor elF2alpha. Mol Cell Biol. 2002;22:7405-16

97. Brewer JW, Diehl JA. PERK mediates cell-cycle exit during the mammalian unfolded protein response. Proc Natl Acad Sci U S A. 2000;97:12625-30.

98. Harding HP, Novoa I, Zhang Y, Zeng H, Wek R, Schapira M, Ron D. Regulated translation initiation controls stress-induced gene expression in mammalian cells. Mol Cell. 2000;6:1099-108.

99. Koritzinsky M, Magagnin MG, van den Beucken T, Seigneuric R, Savelkouls K, Dostie J, Pyronnet S, Kaufman RJ, Weppler SA, Voncken JW, et al. Gene expression during acute and prolonged hypoxia is regulated by distinct mechanisms of translational control. EMBO J. 2006;25:1114-25.

100. Lasko P. Gene regulation at the RNA layer: RNA binding proteins in intercellular signaling networks. Sci STKE. 2003;2003:Re6.

101. Le H, Tanquay RL, Balasta ML, Wei CC, Browning KS, Metz AM, Goss DJ, Gallie DR. Translation initiation factors elF-iso4G and elF-4B interact with the poly(a)-binding protein and increase its RNA binding activity. J Biol Chem. 1997;272:16247-55.

102. Wei CC, Balasta ML, Ren J, Goss DJ. Wheat germ poly(a) binding protein enhances the binding affinity of eukaryotic initiation factor $4 \mathrm{~F}$ and (iso) $4 \mathrm{~F}$ for cap analogues. Biochemistry. 1998;37:1910-6.

103. Goss DJ, Kleiman FE. Poly(a) binding proteins-are they all created equal? Wiley Interdiscip Rev RNA. 2013;4:167-79.

104. Archer SK, Shirokikh NE, Hallwirth CV, Beilharz TH, Preiss T. Probing the closedloop model of mRNA translation in living cells. RNA Biol. 2015;12:248-54.

105. Adivarahan S, Livingston N, Nicholson B, Rahman S, Wu B, Rissland OS, Zenklusen D. Spatial Organization of Single mRNPs at Different Stages of the Gene Expression Pathway. Mol Cell. 2018;72:727-738.e725.

106. Friday AJ, Keiper BD. Positive mRNA translational control in germ cells by initiation factor selectivity. Biomed Res Int. 2015;2015:327963.

107. Hinnebusch AG. Molecular mechanism of scanning and start codon selection in eukaryotes. Microbiol Mol Biol Rev. 2011;75:434-67 first page of table of contents. 
108. Populo H, Lopes JM, Soares P. The mTOR signalling pathway in human cancer. Int J Mol Sci. 2012;13:1886-918.

109. Vadysirisack DD, Ellisen LW. mTOR activity under hypoxia. Methods Mol Biol. 2012;821:45-58.

110. Cerniglia GJ, Dey S, Gallagher-Colombo SM, Daurio NA, Tuttle S, Busch TM, Lin A, Sun R, Esipova TV, Vinogradov SA, et al. The PI3K/Akt pathway regulates oxygen metabolism via pyruvate dehydrogenase (PDH)-E1alpha phosphorylation. Mol Cancer Ther. 2015;14:1928-38.

111. Schneider A, Younis RH, Gutkind JS. Hypoxia-induced energy stress inhibits the mTOR pathway by activating an AMPK/REDD1 signaling axis in head and neck squamous cell carcinoma. Neoplasia. 2008;10:1295-302.

112. Uniacke J, Perera JK, Lachance G, Francisco CB, Lee S. Cancer cells exploit elF4E2-directed synthesis of hypoxia response proteins to drive tumor progression. Cancer Res. 2014;74:1379-89.

113. Moore CE, Mikolajek H, Regufe da Mota S, Wang X, Kenney JW, Werner JM, Proud CG. Elongation factor 2 kinase is regulated by proline hydroxylation and protects cells during hypoxia. Mol Cell Biol. 2015;35:1788-804.

114. Connolly E, Braunstein S, Formenti S, Schneider RJ. Hypoxia inhibits protein synthesis through a 4E-BP1 and elongation factor 2 kinase pathway controlled by mTOR and uncoupled in breast Cancer cells. Mol Cell Biol. 2006;26:3955-65.

115. Rehman G, Shehzad A, Khan AL, Hamayun M. Role of AMP-activated protein kinase in cancer therapy. Arch Pharm (Weinheim). 2014;347:457-68.

116. de Meester C, Timmermans AD, Balteau M, Ginion A, Roelants V, Noppe G, Porporato PE, Sonveaux P, Viollet B, Sakamoto K, et al. Role of AMPactivated protein kinase in regulating hypoxic survival and proliferation of mesenchymal stem cells. Cardiovasc Res. 2014;101:20-9.

117. Kenney JW, Moore CE, Wang X, Proud CG. Eukaryotic elongation factor 2 kinase, an unusual enzyme with multiple roles. Adv Biol Regul. 2014;55:15-27.

118. Zhu H, Yang X, Liu J, Zhou L, Zhang C, Xu L, Qin Q, Zhan L, Lu J, Cheng H, Sun $X$. Eukaryotic elongation factor 2 kinase confers tolerance to stress conditions in cancer cells. Cell Stress Chaperones. 2015;20:217-20.

119. Romero-Ruiz A, Bautista L, Navarro V, Heras-Garvin A, March-Diaz R, Castellano A, Gomez-Diaz R, Castro MJ, Berra E, Lopez-Barneo J, Pascual A. Prolyl hydroxylase-dependent modulation of eukaryotic elongation factor 2 activity and protein translation under acute hypoxia. J Biol Chem. 2012;287: 9651-8.

120. Dever TE, Green R. The elongation, termination, and recycling phases of translation in eukaryotes. Cold Spring Harb Perspect Biol. 2012;4:a013706.

121. Feng $T$, Yamamoto A, Wilkins $S E$, Sokolova $E$, Yates $L A$, Münzel $M$, Singh $P$, Hopkinson RJ, Fischer R, Cockman ME, et al. Optimal translational termination requires C4 Lysyl hydroxylation of eRF1. Mol Cell. 2014;53:645-54.

122. Frolova L, Seit-Nebi A, Kisselev L. Highly conserved NIKS tetrapeptide is functionally essential in eukaryotic translation termination factor eRF1. Rna. 2002;8:129-36

123. Stiebler AC, Freitag J, Schink KO, Stehlik T, Tillmann BA, Ast J, Bölker M. Ribosomal readthrough at a short UGA stop codon context triggers dual localization of metabolic enzymes in Fungi and animals. PLoS Genet. 2014;10:e1004685.

124. Andreev DE, O'Connor PB, Zhdanov AV, Dmitriev RI, Shatsky IN, Papkovsky DB, Baranov PV. Oxygen and glucose deprivation induces widespread alterations in mRNA translation within 20 minutes. Genome Biol. 2015;16:90,

125. Pergola PE, Spinowitz BS, Hartman CS, Maroni BJ, Haase VH. Vadadustat, a novel oral HIF stabilizer, provides effective anemia treatment in nondialysisdependent chronic kidney disease. Kidney Int. 2016;90:1115-22.

126. Provenzano R, Besarab A, Wright S, Dua S, Zeig S, Nguyen P, Poole L, Saikali KG, Saha G, Hemmerich $S$, et al. Roxadustat (FG-4592) versus Epoetin alfa for Anemia in patients receiving maintenance hemodialysis: a phase 2 , randomized, 6- to 19-week, open-label, active-comparator, dose-ranging, safety and exploratory efficacy study. Am J Kidney Dis. 2016;67:912-24.

127. Locatelli F, Fishbane S, Block GA, Macdougall IC. Targeting hypoxiainducible factors for the treatment of Anemia in chronic kidney disease patients. Am J Nephrol. 2017:45:187-99.

128. Koh MY, Spivak-Kroizman T, Venturini S, Welsh S, Williams RR, Kirkpatrick DL, Powis G. Molecular mechanisms for the activity of PX-478, an antitumor inhibitor of the hypoxia-inducible factor-1alpha. Mol Cancer Ther. 2008;7:90-100.

129. Palayoor ST, Mitchell JB, Cerna D, Degraff W, John-Aryankalayil M, Coleman CN. PX-478, an inhibitor of hypoxia-inducible factor-1alpha, enhances radiosensitivity of prostate carcinoma cells. Int J Cancer. 2008;123:2430-7.

130. Tibes R, Falchook GS, Hoff DDV, Weiss GJ, lyengar T, Kurzrock R, Pestano L, Lowe AM, Herbst RS. Results from a phase I, dose-escalation study of PX478, an orally available inhibitor of HIF-1a. J Clin Oncol. 2010;28:3076.
131. Duan JX, Jiao H, Kaizerman J, Stanton T, Evans JW, Lan L, Lorente G, Banica M, Jung D, Wang J, et al. Potent and highly selective hypoxia-activated achiral phosphoramidate mustards as anticancer drugs. J Med Chem. 2008; 51:2412-20.

132. Laubach JP, Liu CJ, Raje NS, Yee AJ, Armand P, Schlossman RL, Rosenblatt J, Hedlund J, Martin M, Reynolds C, et al. A Phase I/II Study of Evofosfamide, A Hypoxia-activated Prodrug with or without Bortezomib in Subjects with Relapsed/Refractory Multiple Myeloma. Clin Cancer Res. 2019;25:478-86.

133. Kummar S, Raffeld M, Juwara L, Horneffer $Y$, Strassberger A, Allen D, Steinberg SM, Rapisarda A, Spencer SD, Figg WD, et al. Multihistology, target-driven pilot trial of Oral Topotecan as an inhibitor of hypoxiainducible factor-1a (HIF-1a) in advanced solid tumors. Clin Cancer Res. 2011; 17:5123-31.

134. Rapisarda A, Zalek J, Hollingshead M, Braunschweig T, Uranchimeg B, Bonomi CA, Borgel SD, Carter JP, Hewitt SM, Shoemaker RH, Melillo G. Schedule-dependent inhibition of hypoxia-inducible factor-1alpha protein accumulation, angiogenesis, and tumor growth by topotecan in U251-HRE glioblastoma xenografts. Cancer Res. 2004;64:6845-8.

135. Rapisarda A, Uranchimeg B, Scudiero DA, Selby M, Sausville EA, Shoemaker $\mathrm{RH}$, Melillo $\mathrm{G}$. Identification of small molecule inhibitors of hypoxia-inducible factor 1 transcriptional activation pathway. Cancer Res. 2002;62:4316-24.

136. Herben VM, ten Bokkel Huinink WW, Beijnen JH. Clinical pharmacokinetics of topotecan. Clin Pharmacokinet. 1996;31:85-102.

137. Keefe SM, Hoffman-Censits J, Cohen RB, Mamtani R, Heitjan D, Eliasof S, Nixon A, Turnbull B, Garmey EG, Gunnarsson O, et al. Efficacy of the nanoparticle-drug conjugate CRLX101 in combination with bevacizumab in metastatic renal cell carcinoma: results of an investigator-initiated phase IIla clinical trial. Ann Oncol. 2016;27:1579-85.

138. Chao J, Lin J, Frankel P, Clark AJ, Wiley DT, Garmey E, Fakih M, Lim D, Chung $V$, Luevanos $E$, et al. Pilot trial of CRLX101 in patients with advanced, chemotherapy-refractory gastroesophageal cancer. J Gastrointest Oncol. 2017:8:962-9.

139. Voss MH, Hussain A, Vogelzang N, Lee JL, Keam B, Rha SY, Vaishampayan U, Harris WB, Richey S, Randall JM, et al. A randomized phase II trial of CRLX101 in combination with bevacizumab versus standard of care in patients with advanced renal cell carcinoma. Ann Oncol. 2017;28:2754-60.

140. Pham E, Yin M, Peters CG, Lee CR, Brown D, Xu P, Man S, Jayaraman L,

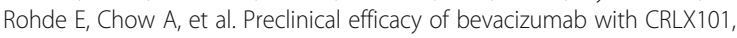
an investigational nanoparticle-drug conjugate, in treatment of metastatic triple-negative breast Cancer. Cancer Res. 2016;76:4493-503.

141. Pham E, Birrer MJ, Eliasof S, Garmey EG, Lazarus D, Lee CR, Man S, Matulonis UA, Peters CG, Xu P, et al. Translational impact of nanoparticle-drug conjugate CRLX101 with or without bevacizumab in advanced ovarian cancer. Clin Cancer Res. 2015;21:808-18.

142. Wallace EM, Rizzi JP, Han G, Wehn PM, Cao Z, Du X, Cheng T, Czerwinski RM, Dixon DD, Goggin BS, et al. A small-molecule antagonist of HIF2alpha is efficacious in preclinical models of renal cell carcinoma. Cancer Res. 2016;76: 5491-500.

143. Cho H, Du X, Rizzi JP, Liberzon E, Chakraborty AA, Gao W, Carvo I, Signoretti S, Bruick RK, Josey JA, et al. On-target efficacy of a HIF-2alpha antagonist in preclinical kidney cancer models. Nature. 2016;539:107-11.

144. DeFatta RJ, Nathan CO, De Benedetti A. Antisense RNA to elF4E suppresses oncogenic properties of a head and neck squamous cell carcinoma cell line. Laryngoscope. 2000;110:928-33.

145. Moerke NJ, Aktas H, Chen H, Cantel S, Reibarkh MY, Fahmy A, Gross JD, Degterev A, Yuan J, Chorev M, et al. Small-molecule inhibition of the interaction between the translation initiation factors elF4E and elF4G. Cell. 2007;128:257-67.

146. Graff JR, Konicek BW, Vincent TM, Lynch RL, Monteith D, Weir SN, Schwier P, Capen A, Goode RL, Dowless MS, et al. Therapeutic suppression of translation initiation factor elF4E expression reduces tumor growth without toxicity. J Clin Invest. 2007;117:2638-48. 